\title{
Violência e resistência na narrativa de mulheres argentinas
}

\author{
Márcia Paraquett \\ Universidade Federal da Bahia \\ marciaparaquett@gmail.com \\ https://orcid.org/0000-0002-7474-6177
}

RESUMO: O objetivo deste artigo é refletir a partir de narrativas de duas mulheres argentinas: Liliana Heker, por meio de seu romance El fin de la historia (1996) e Norma Morandini, por intermédio de seu livro documentário El harén. Los árabes y el poder politico en la Argentina (1998). Cada uma, a partir de sua experiência pessoal e das especificidades de sua escrita, me ajudam a comprovar que a literatura argentina sempre esteve comprometida com questões históricas, observando-se, em particular, a década de noventa do século passado, quando aquele país recém saía de sua ditadura militar (19741983). Ainda que as duas obras abordem contextos diferentes com relação à ditadura militar, as narrativas ressaltam a violência e as formas de resistência dos argentinos finisseculares.

PALAVRAS-CHAVE: Ditadura militar. Argentina. Literatura Feminina.

\section{VIOLENCE AND RESISTANCE IN THE NARRATIVE OF ARGENTINE WOMEN}

ABSTRACT: The aim of this article is to reflect from the narratives of two Argentine women: Liliana Heker, through her novel El fin de la historia (1996) and Norma Morandini, through her report book $E l$ harén. Los árabes y el poder politico en la Argentina (1998). Each one, from her personal experience and the specificities of her writing, helps me to prove that Argentine literature has always been committed to historical issues, observing, in particular, the nineties of the last century, when that country recently emerged from its military dictatorship (1974-1983). Although the two works address different contexts in relation to the military dictatorship, the narratives highlight the violence and forms of resistance of the end of the century Argentines.

KEYWORDS: Military dictatorship. Argentina. Women's Literature. 
Este texto aborda a repressão e as resistências no campo artístico, colocando o foco em narrativas de duas mulheres argentinas, que viveram na Argentina no período de ditadura militar entre 1976 e 1983, que, se comparado à ditadura militar brasileira, que ocorreu entre 1964 e 1985, a ditadura na Argentina foi mantida por um período menor. No entanto, o menor período daquela ditadura não a fez menos violenta que a brasileira, já que, afinal, o Cone Sul de nossa querida América Latina se uniu naquela brutalidade, silenciando e matando os jovens de minha geração. Falar, portanto, das ditaduras militares da América Latina é falar de minha própria história.

Em 2015' , finalmente, publiquei um livro, organizado juntamente com Savio Siqueira, que recuperou a memória de nossa geração. A única pretensão era criar um espaço de fala, por onde pudéssemos expurgar a dor silenciada por tantos anos de repressão. Minha vida pessoal não foi afetada diretamente com a violência física, mas a moral e a psicológica, todos sentimos. Não será por outra razão que escolhi como tema para meu Doutorado em Literaturas de Língua Espanhola, concluído na Universidade de São Paulo, em 1997, o romance histórico daquela década tão marcada pela produção de uma literatura que gritou sua dor. Ainda hoje, não resisto ao tema e sempre procuro ouvir e ler quem viveu repressão de ditadores, sejam militares ou civis. Aliás, essas duas categorias estiveram juntas na ditadura brasileira, tanto que há muitos historiadores que preferem falar em ditadura civil-militar, embora eu, intencionalmente, continue falando apenas dos militares, porque foram eles que ocuparam os espaços formais de poder, ainda que tenham sido apoiados por muitos civis, igualmente fascistas, como os ditadores fardados.

As duas mulheres/autoras que escolho para analisar suas respectivas obras são Liliana Heker e Norma Morandini. A primeira nasceu em Buenos Aires, no ano de 1943, sendo autora de contos, romances e ensaios. Defino-me por seu romance El fin de la historia, publicado em 1996. A segunda nasceu em Córdoba, no ano de 1948, jornalista de formação, tendo sido, inclusive, correspondente de O Globo, jornal brasileiro. Escolho discutir seu ensaio El Harén. Los árabes y el poder político en la Argentina ${ }^{2}$, publicado em 1998, mas chamo atenção para a importância de outra obra de Morandini que contribui para a temática desse dossiê: De la culpa al perdón, publicado em 2012 e classificado no gênero autobiografia.

As duas obras que selecionei foram produzidas por duas mulheres da mesma geração, tendo vivido, portanto, a ditadura militar argentina ao mesmo tempo, embora cada uma tenha feito suas escolhas de forma livre ou imposta pelo regime. Liliana Heker permaneceu na Argentina, pois dirigia, juntamente com Abelardo Castillo, a Revista Escarabajo de oro, tendo sido sua subdiretora desde 1964. A revista funcionou muito bem até 1974, tendo recebido figuras importantes da América Latina como autores ou no seu conselho editorial, como Julio Cortázar, Carlos Fuentes, Miguel Ángel Asturias, Juan Goytisolo, Ernesto Sábato, Roberto Fernandez Retamar e outros. Foi considerada uma

1 Refiro-me a PARAQUETT, M.; SIQUEIRA, S. (Orgs). Caminhando e contando. Memória da ditadura brasileira. Salvador: EDUFBA, 2015. O livro já se encontra disponível em https://repositorio.ufba.br/ri/handle/ri/31866.

2 Ao longo do artigo, vou valer-me apenas da primeira parte do título: El Harén. 
revista de resistência durante a ditadura, atraindo novos escritores como Ricardo Piglia (1941-2017) e Silvia Iparraguirre (1947), mas não resistiu, tendo sido necessário criar uma nova revista, El Ornitorrinco, em 1984, quando então se deu uma célebre polêmica entre ela e Julio Cortázar, que resultou em muita discussão no mundo literário latino-americano, no qual incluo o interessante artigo Exilio poético y exilio político: la polémica entre Liliana Heker y Julio Cortázar en la Revista Cultural El Ornitorrinco, de Adrián Ferrero ${ }^{3}$. Em resumo, e sem que eu tome partido, Cortázar questionou Heker sobre o serviço que estaria prestando aos ditadores ao se manter no país, enquanto ela se defendeu dizendo que sua permanência na Argentina mantinha viva a literatura que defendia.

Norma Morandini fez outros percursos, já que precisou exilar-se depois do desaparecimento de dois de seus irmãos, assassinados pelo regime. Ao voltar, dedicou-se à carreira política, tendo sido deputada por Córdoba (2005-2009) e senadora nacional, o que a levou a ser candidata à vice-presidência da nação, como representante da Frente Ampla Progressista, no ano de 2011.

Devido à sua profissão e aos recorridos que precisou fazer pelo mundo, conheceu e casou-se com o jornalista brasileiro, Flávio Tavares, um dos presos políticos que foram trocados pelo embaixador norte-americano, Charles Burke Elbrick, sequestrado pelo MR-8 em 1969. Flávio é autor de Memórias do esquecimento (1999), livro documentário, assim como o filme dirigido por seu filho, Camilo Tavares, O dia que durou 21 anos, de $2012^{4}$.

São, portanto, duas mulheres que viveram experiências diferentes, mas ambas marcadas pela violência da ditadura militar argentina. É preciso que se ressalte ainda que o livro de Norma Morandini não se refere, especificamente, à ditadura militar argentina, como ocorre no romance de Liliana Heker. Como se verá, a autora se ocupa do período em que Carlos Menem esteve como presidente daquele país (1989 a 1999), lembrando que ele foi o segundo presidente eleito após a ditadura, carregando uma série de valores morais que ainda não tinham sido abortados pelo poder político. Aliás, vale a pena, pensar que não se apaga com facilidade o rastro deixado por um longo período ditatorial, o que sempre me levou a compreender que aquela escrita de Morandini trazia uma Argentina ainda maculada pelos estragos dos generais. Se quisermos fazer uma comparação, o presidente brasileiro eleito após a ditadura brasileira foi Collor de Mello (1990-1992), impedido por corrupção.

Antes, no entanto, de propor algumas reflexões sobre as duas narrativas por mim selecionadas, preciso observar que, no meu ponto de vista, a literatura latino-americana, daquele período, conviveu com duas questões fundamentais: a linguagem e a utopia. Meu interesse por essa temática ganhou forças durante a realização do Doutorado, a partir do romance Jaguar en llamas (1989), do escritor guatemalteco, Arturo Arias, quando pude perceber que havia uma tendência naquela geração de escritor (as) a considerar a linguagem como um elemento ativo nas narrativas. Tratava-se de um processo metalin-

$3 \mathrm{O}$ referido artigo encontra-se disponível em https://perio.unlp.edu.ar/ojs/index.php/question/article/view/442, com consulta em $09 / 02 / 2021$.

$4 \mathrm{O}$ documentário já se encontra disponível em diferentes suportes, como em https://www.youtube.com/watch?v=hXxqBibwgAg, com consulta em 09/02/2021 
guístico, que trazia a palavra ao centro da narrativa, modelo que ganhou muita força na década de noventa.

Arturo Arias já duvidava que a escritura, literária ou histórica, pudesse registrar a verdade factual, na medida em que, depois de Mikail Bakhtin, o conhecimento do dialogismo não permitiria a inocência da palavra. Lembremos que o linguista russo propõe que em cada palavra existem sempre duas vozes: a do "eu" e a do "outro". Nesse sentido, a palavra não é primária, pois guarda em si milhões de sentidos anteriores, cedidos por ideologias também anteriores. É função do falante ou do(a) escritor(a) recolher todas essas vozes, todos os estilos de representação da língua e organizá-los de maneira que possam se acomodar na ideologia de quem a utiliza. Afirma Bakhtin (1993) que todas as palavras de uma linguagem são vozes sociais e históricas. Elas expressam a posição sócio-ideológica diferenciada do(a) usuário(a), em meio aos diferentes discursos de sua época. A isso, como sabemos, se chamou dialogismo.

Ao final daquela tese, pude comprovar que romances como Jaguar en llamas denunciam a impossibilidade de se escrever a história, considerando-se a função dialógica da palavra e o poder das diferentes ideologias ao longo do tempo histórico. Levada por essa temática, novas leituras históricas e literárias me encaminharam a outra perspectiva, em que se pressentia não só 'o fim da história', como queriam alguns, mas a inoperância da linguagem e a vitória do silêncio. Essa percepção, a princípio paradoxal, despertou minha curiosidade e me levou à leitura de narrativas de tema histórico, publicadas na última década do século passado.

A relação História e Literatura é frequente na literatura hispano-americana, como se sabe. Seu alvo preferido sempre foi o romance histórico, utilizado aqui com o sentido prático, dado por Alexis Márquez Rodríguez (1991), que considera duas condições básicas para sua constituição: que seja um romance, portanto, ficção, invenção do romancista; e que se fundamente em fatos históricos, não fictícios, não inventados.

O romance histórico hispano-americano nasceu sob o modelo scottiano, até que Alejo Carpentier impôs seu esquema, determinando o que hoje se conhece como o Novo Romance Histórico. $\mathrm{O}$ modelo carpentiano sofreu muitas modificações, chegando às paródias carnavalizadas, produções literárias principalmente dos anos de 1980. Esse tipo de paródia ridiculariza a palavra autoritária, aquela que em algum momento foi reconhecida como verdade.

Creio que, seguindo uma corrida natural, hoje, muitos do(a)(s) escritor(a)(s) de romances de tema histórico querem trazer a questão do sentido e do poder das palavras ao centro de suas narrativas. Já não há a inocência de que a verdade histórica será registrada pela literatura ou mesmo pela história. Hoje, se acredita na existência de narrativas históricas ou discursos históricos, nos quais a subjetividade da linguagem não garante o registro da verdade factual. No entanto, embora conscientes do limite da palavra e do dialogismo da linguagem, o(a)(s) escritor(a)(s) acredita (m) que a literatura colabora para 
o registro de sua história. E por isso, a narrativa literária histórica, por sorte, se mantém viva.

\section{O FIM DA HISTÓRIA DE LILIANA HEKER5}

\section{[...] amaba las palabras porque eran capaces de preservar cada cosa en su perfección}

(HEKER, 1996. p. 23)

El fin de la historia se constrói a partir das relações entre duas personagens femininas: Diana Glass e Leonora, amigas desde os tempos da Escola Normal. Diana, cujo sobrenome, em inglês, significa óculos, é míope e, com sua visão polissêmica, escreve um romance no qual Leonora é a protagonista. Portanto, o romance de Liliana Heker se constitui da junção de dois discursos diferentes e apartados, que desestabilizam o(a) leitor(a) em deslizes intencionais.

Leonora é uma militante de esquerda que, na juventude, sonhou com a revolução como saída para um mundo justo. Desde os tempos da escola, a capacidade de liderança e de persuasão de Leonora fizeram com que Diana, sua companheira e principal amiga, visse nela o modelo de uma geração que tinha como meta modificar o mundo.

A meta-produção narrativa é um dos eixos fundamentais do romance, além de outros dois também muito importantes: a preocupação com a exatidão da palavra e a visão a partir da miopia. Começo, destacando que há muitas palavras entre aspas que se apresentam como objetos de observação. Estão ali, intencionalmente, ocupando o centro da atenção de personagens, narradores e, claro, de leitores. Entre elas, se destacam "mar", "madre" e "desaparecido", palavras vitalmente relacionadas à história da Argentina daquele momento.

"Mar", no texto, está relacionada a "capitán" (capitão). No contexto do romance suas presenças se justificam, porque Liliana Heker as associa ao mundo real e imaginário. Me explico: as personagens femininas, em sua infância, davam a essas palavras um sentido de fantasia, próprio ao mundo da literatura infantil, quando os capitães comandavam os navios que carregavam as ilusões por mares inventados. No mundo da realidade, essas palavras estão associadas ao lugar onde Leonora esteve presa e torturada: a Escola da Marinha. Como se vê, os capitães da infância se transformam nos torturadores, levando a escritora a se manifestar quanto à ruptura de sentido e o drástico roubo de significação. Lamenta-se que já não se possa dizer "mar" e "capitán", sem que o novo sentido dessas palavras destrua a ilusão de um mundo em paz.

Quanto à palavra "madre" (mãe), todos sabemos onde está a conexão estabelecida. Refere-se às "Madres de la Plaza de Mayo" (Mães da Praça de Maio), movimento nascido do silêncio em palavras e de denúncia em ação. Mães dos filhos mortos pelo sistema e mães que, nas celas, tinham seus filhos recém-nascidos, roubados pelas famílias de militares $^{6}$. O pretexto encontrado por Liliana Heker para pôr em evidência essa palavra

\footnotetext{
$5 \mathrm{O}$ item resulta de um trabalho adaptado, apresentado originalmente no Coloquio Internacional Género, raza y clase en la Cultura latinoamericana y caribeña, em Habana/Cuba, no ano de 1999, sob o título La palabra y 'El fin de la historia' de Liliana Heker.

6 Há um filme que retrata duramente essa realidade. Refiro-me a La historia oficial, de 1985, dirigido por Luis Puenzo, vencedor do prêmio Globo de Ouro, na categoria Melhor Filme Estrangeiro.
} 
revela aos leitores a mais reprimível ação denunciada no romance: a traição. Ou a sobrevivência. Me explico outra vez: Leonora não resiste à tortura. Passado um tempo, troca a/o "capucha" (capuz) e a/o "picana" (bastão elétrico) pela vida de sua filha, passando a colaborar com o sistema. Traição ou sobrevivência? Esse conflito está presente na narrativa de Diana Glass que, incansavelmente, busca pelo 'fim da história'. A palavra "madre", no entanto, não foi roubada pelo sistema autoritário. Muito ao contrário, as Mães da Praça de Maio são um símbolo de resistência, já que seu sentido primeiro se fez mais forte, mais político e mais denunciador.

Observemos a terceira das palavras aqui destacadas. Estar ou ser "desaparecido"? Essa questão morfossintática foi modificada pelo sistema autoritário da Argentina, já que "desaparecer" era, desde os tempos do gênio da lâmpada maravilhosa, uma ação ininterrupta, quando se podia ver aparecer e desaparecer pessoas, coisas, lugares. Mas, os "desaparecidos" argentinos não voltaram a ver a luz. Este verbo de sentido transitório passou a ser permanente, já que naquela Argentina, o que estava desaparecido, era desaparecido. Ao saber que sua amiga Leonora estava desaparecida, Diana Glass se dá conta pela primeira vez que essa palavra "era una lava en plena expansión que más se manifestaba por la ferocidad de cada contacto que por una posible virtud simbólica" (HEKER, 1996, p. 93).

Ainda que minhas reflexões tenham sido muito breves, uma coisa se pode afirmar de maneira conclusiva: todas as palavras destacadas pela autora, sem exceção, estão ali com a intenção de resgatar seus sentidos, retirando-lhes a significação autoritária com que aquele sistema político as danificou.

Outro eixo sobre o qual se constrói a obra de Heker é a visão de Diana Glass que, a partir da miopia, modifica sua realidade. Ela se explica, dizendo que para compreender os equívocos vividos pelos míopes, é preciso se meter em sua subjetividade. A realidade, para eles, necessita ser imaginada. Propositalmente, a personagem não coloca os óculos, porque para ela seria "como sustituir un paisaje de Cézanne por una tarjeta postal ya que la visión del miope es mucho más bella que la del humano normal". Afirma também que "lo real y lo fantástico son entonces conceptos totalmente inútiles porque todo límite queda abolido. Las formas son versátiles y dinámicas. Como si el mundo estuviese hecho por algún impresionista exacerbado" (HEKER, 1996, p. 201).

Mas que importância poderá ter esse fato para a compreensão do romance? Diana e Leonora passam muito tempo sem encontrar-se e, nesse período, Diana sabe que a amiga está presa e a imagina morta ou destroçada pelas torturas. Quando a reencontra, tempos depois, Leonora é outra: trocou sua ideologia, suas crenças, suas roupas, modificando-se radicalmente. Diana, então, relaciona o horror de sua constatação com a deformação natural de um(a) míope.

A opção por ver a realidade de forma impressionista se contrapõe à dura necessidade de reconhecer que Leonora, a representação mítica de uma geração que pensou mudar o mundo com suas revoluções, também tinha sua debilidade. Não ter resistido à 
pressão dos militares, assim como o novo discurso de Leonora, levam Diana a preferir uma realidade imaginada, porque assim pode construí-la de maneira menos sofrida.

Para uma plena compreensão do romance de Liliana Heker, é preciso relacionar seu título com a intenção de escrevê-lo a partir da miopia. O fim da história, aqui, não é apocalíptico, nem reproduz a visão de Francis Fukuyama ${ }^{7}$. O fim da história para Liliana Heker está diretamente relacionado com a mesma sensação que a miopia trouxe ao texto. Nas duas situações, o que querem as narradoras das duas novelas escritas em simbiose é encontrar um fim para a história do autoritarismo, da traição, da opressão, da violência, do medo, da insegurança, da miséria. Olhar a realidade, colocando-se os óculos, significa não encontrar o fim dessa história.

Vale, então, uma pergunta: Estaria o romance de Liliana Heker propondo que abandonemos a realidade para substituí-la por outra irreal e que nos faça mais felizes? Estaria propondo a alienação ideológica? Minha resposta é não. O conflito vivido por Diana Glass e a dor de ter dado conta de que sua amiga havia traído seus ideais revolucionários revelam que a realidade não é aquela sonhada e imaginada na juventude. Depois de ter constatado que Leonora nunca quis fazer a revolução que ela acreditava, Diana passa a usar os óculos. Colocar fim à história é também compreendê-la a partir dessa perspectiva. E, nessa atitude, ao meu juízo, o discurso de Liliana Heker se apresenta com bastante maturidade. Se não fosse assim, como se justificaria sua contribuição para a permanência da utopia?

Não me refiro à utopia no seu sentido etimológico grego, como um lugar inexistente, um país que não se encontra em nenhuma parte. O significado histórico das utopias, segundo Jerzi Szacki (1972), depende da medida em que são capazes de contribuir para que a consciência social se assegure do caráter problemático da ordem existente e da necessidade de escolha entre ela e alguma outra.

O fato é que, às portas do terceiro milênio, aquela literatura lutava por recuperar o uso pleno e irrestrito da palavra. O romance de Liliana Heker, de acordo com o que já estava anunciado desde a epígrafe utilizada por mim, confirma que cabe às palavras serem capazes de preservar cada coisa em sua perfeição.

\section{OHARÉMDE NORMA MORANDINI ${ }^{8}$}

¿Será que hay una parte importante de nuestros compatriotas a los que no les importa que haya corrupción, a los que no les importa el autoritarismo? Esto es lo que más me perturba. (Norma Morandini) ${ }^{9}$

\footnotetext{
7 A visão de Francis Fukuyama, ex-assessor de Defesa do Departamento de Estado dos Estados Unidos, publicada pela primeira vez em seu artigo O fim da história?, em 1989, e posteriormente em seu livro O fim da história e o último homem, em 1992, assume que a humanidade, após a legitimidade da democracia liberal, à luz da vitória do capitalismo sobre o comunismo, a monarquia e o fascismo, chegou ao fim de sua evolução ideológica, portanto, ao final de sua história. Essa visão é criticada e rejeitada por muitos intelectuais que não reconhecem a universalidade da democracia liberal, devido, entre outros motivos, à desigualdade econômica gerada pelo capitalismo. Sabiamente, Eduardo Fracchia nega a filosofia de Fukuyama, afirmando que ele "escribe desde y para el poder que representa, de ahí que sea lógico que defienda a ultranza, y con los medios que considere más aptos, su posición. Y esto no tiene por qué escandalizarnos. Lo que no es comprensible es que nosotros, habitantes de países del tercer mundo, confiemos ciegamente en estas promesas de liberación, o bien de incorporación al deslumbrante "orden" del primer mundo" (FRACCHIA, Eduardo. Filosofia de la Resistencia. Corrientes: EUDENE, 1997, p.123).

8 Item adaptado de publicação anterior: ALVES, Ivia (Org.), Anais do VIII Seminário Nacional Mulher e Literatura, UFBA: Salvador, 2001. (CD Rom)

9 Retirado de https://www.cadena3.com/noticia/entrevista-a-fondo/15-frases-sobre-politica-corrupcion-y-derechos-humanos_210963, com consulta em 10/02/2021
} 
El Harén é uma escritura que ultrapassa as barreiras da objetividade jornalística, sem perder a clareza e o rigor dos fatos. Uma narrativa que se escreve por razões que a própria autora anuncia já na introdução de seu livro:

Es probable que si no tuviera un abuelo libanés, una madre criada dentro de un grupo familiar protector, con patriarcas y prohibiciones, tías casadas y solteronas, sacrificadas unas por los maridos, otras, por los hermanos, mis observaciones y conclusiones hubiesen sido diferentes. Desatar mis nudos, a la edad en la que los seres humanos comenzamos a caminar hacia los despojos, me permitió tejer mi propia red: no me siento "paisana". Sólo una mujer, nacida en la Argentina, hecha de varias madejas. Como todos. (MORANDINI, 1998, p. 14)

Embora Norma Morandini afirme não se sentir conterrânea dos árabes porque é apenas uma mulher, nascida na Argentina, seus olhos e sua voz guardam a magia de Sherazade. Vê-la e ouvi-la é o suficiente para confirmar seu poder de sedução. Frente a uma plateia de mais de 1000 pessoas a conheci, falando sobre a palavra e sua capacidade de fazer a história. A suavidade de sua voz e a força de seu olhar, juntos, produziam uma força que magnetizava o público e, claro, a mim também. Desculpem se os vou decepcionar, contando-lhes que El Harén não é uma história passada nos esplêndidos palácios orientais, com seus musculosos eunucos e suas lindas mulheres com véus, roupas insinuantes e cadências sensuais. Ainda no prólogo, Norma Morandini nos alerta para o sentido que quis dar a seu título, afirmando que esse harém que conhecemos através da fantasia ocidental, revelado nos filmes hollywoodianos, foi, na verdade, o harém imperial, diferente do harém doméstico, e que se mantém ainda hoje. Vejamos o que diz a autora:

El harén es la vivienda donde el hombre muzulmán aloja a su familia, sus esposas, sus hijas, sus parientes, una inmensa casa de patios interiores y grandes galerías donde hombres y mujeres viven en dos mundos separados, con sus deberes y sus áreas perfectamente delimitados (MORANDINI, 1998, p. 203).

Nesses palácios, os homens cuidavam para que suas mulheres não precisassem sair à rua. Entre mármores e fontes, bons alimentos e vestidos bonitos, era preciso garantir que as mulheres compartilhassem daqueles aprisionamentos domésticos. Afinal, acreditavam eles, as mulheres não precisavam de mais nada para serem felizes. Apenas as mais pobres poderiam circular, quando, levadas pela necessidade do trabalho, viviam suas relativas liberdades.

É esse harém doméstico que vai determinar o sentido que Norma Morandini quer dar ao título de seu livro. El Harén é a metáfora do Estado argentino. O lugar onde Carlos Menem (Argentina, 1930) protegeu seus familiares, muitos deles designados para cargos públicos durante seus dois mandatos presidenciais.

É a própria Norma Morandini que se pergunta sobre qual teria sido o motivo que a levara a escrever El Harén. Um avô libanês e o prazer de comer quibes junto à família poderiam justificar tal façanha, mas ela sabe que, na verdade, sua intenção era a de desfazer o nó de sua identidade e a de compreender melhor a história do poder político de seu país. Trata-se de uma narrativa de caráter jornalístico que quer responder a perguntas 
que subjazem naquela sociedade argentina, acostumada a conviver com a presença dos árabes no centro de seu poder político.

Mohamed Alí Seineldín, um general do exército argentino que participou do processo de tortura e da guerra das Malvinas; Carlos Menem, presidente por dois mandatos e ironicamente identificado por Morandini como "playboy dos trópicos"; e, Zulema Yoma, a ex-mulher do presidente, são os personagens que permitem o passeio pela história da imigração árabe, tendo esta última merecido, por parte da autora, um olhar que a revela despojada de sua função de primeira dama para adquirir um novo poder: o de ser uma mãe em luto. Esses personagens foram escolhidos porque os três acreditam na infalibilidade do destino; creem que a vida deve ser percorrida com paciência e resignação; e que o destino lhes reservou um lugar destacado, próprio aos escolhidos.

Para essas reflexões, no entanto, fiz um recorte no texto, privilegiando as vozes femininas: a da mulher árabe, a da mulher árabe-argentina e a da mulher jornalista, atenta e comprometida com as questões sociopolíticas de seu país.

O capítulo referente às mulheres árabes recebe dois fragmentos do Alcorão, o livro sagrado do Islã, como epígrafes. Dois fragmentos controversos que revelam a dicotomia em que se encerra a mulher na cultura oriental. Enquanto o primeiro afirma que "o melhor de minha comunidade é que tem mais mulheres", o segundo ameaça dizendo: "se não lhes obedecem, batam nelas, prendam-nas e as privem de água e alimento até que Alá as leve" (MORANDINI, 1996, p. 86). Essa controvérsia, mulher que é ao mesmo tempo o bem e o mal, não é específica da cultura árabe, sabemos todos. No entanto, dentre as culturas modernas, talvez eles sejam os mais conservadores. Enquanto a beleza e a astúcia das mulheres são valorizadas, ressalta-se sua condição de viverem subjugadas a seus pais ou a seus maridos.

Mas não se pode compreender a mulher árabe sem relacionar sociedade com religião. E não se pode reduzir o tema da liberdade da mulher com a imposição do véu que cobre seus rostos. Isso é tão limitador quanto estabelecer parâmetros entre a liberdade da mulher ocidental e a desnudez de seus corpos. Sabemos que a questão é muito mais complexa, já que a liberdade está para além de véus e topless.

Hoje as mulheres árabes não vão às mesquitas argentinas usando véus, mas ainda cobrem suas cabeças com lenços que ocultam seus rostos. Também não questionam a tradição que as mandam rezar atrás dos homens ou separadas deles por uma cortina. Segundo Morandini, isso se explica porque é necessário que o corpo da mulher, visto ainda como diabólico, não se interponha entre as coisas de Deus. A pesquisa da jornalista é muito cuidadosa, resultando em um texto que procura observar os fatos com distanciamento e objetividade. Mas é fácil que se encontre a eu poética revelada nas preocupações que a cercam. Chamou-me atenção a ponte que Morandini estabelece com os fundamentalistas do fim do século XX. Como mulher ocidental, ela foi ao Alcorão buscar as páginas relativas às mulheres. As suras mais longas estão dedicadas a elas e suas relações amorosas com os homens. Para justificar seus ataques às mulheres e também aos poetas, 
os fundamentalistas vão ao livro sagrado confirmar a maldição desses seres que são fonte de todo mal ou desafio da palavra de Deus. Para o muçulmano o verdadeiro pecado é não crer em Deus. A sexualidade é reprimida porque toda fonte de energia deve ser direcionada a Deus. E a mulher, por ser diabólica, desvia a atenção do homem que deve estar preparado para a oração e para a guerra, consequências diretas do fanatismo.

Mas é preciso compreender que a sexualidade não é pecaminosa. Os homens, e também as mulheres, precisam estar satisfeitos, desde que os atos sexuais sejam realizados legalmente, ou seja, dentro do casamento. Mas é impossível não remeter às diferenças de direito que a lei do matrimônio dá aos homens e mulheres no Islã. Segundo a socióloga marroquina Fátima Mernissi, citada por Norma Morandini, a poligamia é promíscua e a possibilidade do homem desfazer-se de sua mulher caracteriza a permissividade daquela cultura que a sociológica classifica como bárbara. A partir dessa acusação, Morandini estabelece um paralelo entre as mulheres ocidentais e orientais, afirmando que as primeiras são exaltadas apenas como mães, tendo seus valores intelectuais e sociais abafados, enquanto as segundas são vistas apenas como rainhas, meninas eternas, protegidas por seus pais, esposos ou irmãos. Todas, portanto, limitadas e prisioneiras.

Feitos esses comentários, que ajudam a contextualizar o livro de Morandini, passo a estabelecer relações entre as duas mulheres árabes-argentinas: Zulema Yoma e Norma Morandini. O que mais me chamou atenção no capítulo referente à ex-mulher de Carlos Menem, foi o trato dado pela escritora àquela mulher. Fica claro que a convivência resultante das entrevistas determinou uma cumplicidade entre entrevistadora e entrevistada. Cumplicidade nascida, seguramente, do olhar da escritora-mulher. O capítulo se abre com uma discussão partidarista, quando Morandini se coloca ao lado da mulher repudiada pelo marido árabe, ressaltando a novidade em território argentino. O olhar da escritora se volta para a rebeldia de Zulema que declarou guerra ao marido presidente diante do silêncio da nação. Indignada, teria dito: "se o povo permite isso, esperem por qualquer coisa" (MORANDINI, 1998, p.133). Morandini ainda compara as críticas feitas a Zulema Yoma e a Carlos Menem, observando que elas são diferentes. O que se diz da mulher, em situações similares, não se diria do homem, o que nela desonra, nele enaltece. Incomoda Morandini, que se diga: 'essa mulher está louca'. Sabe ela, assim como eu, que esse adjetivo é utilizado sempre que as mulheres saem de suas molduras pré-fabricadas pelo patriarcado.

O relacionamento de Zulema e Menem nunca foi tranquilo. O casamento foi feito por procuração, porque ela estava vivendo na Síria, embora tenha nascido em La Rioja. Já estavam separados quando ele se apresentou como candidato à presidência do país e, a pedido da Igreja Católica, reconciliaram-se e se casaram como manda a tradição religiosa da Argentina. Construía-se uma relação de aparências para garantir a legitimidade da eleição. Passados poucos anos, Carlos Menem a repudia outra vez, exigindo que ela abandone a residência presidencial. $\mathrm{O}$ filho, Carlitos, se alia à resistência da mãe e pu- 
blica uma carta emocionada, cobrando de seu pai a responsabilidade de chefe de família que the parecia ter sido roubada pela ânsia do poder político.

Esse episódio lembra, em muito, o casamento de Dulce Figueiredo (1928-2011), esposa de João Batista Figueiredo (1918-1999), o último general a presidir o Brasil durante a ditadura militar. Dulce, segundo se dizia, não estava casada com Figueiredo fazia algum tempo, mas o fato de estar ocupando aquele cargo, o obrigou a retomar socialmente aquela relação, embora ficasse evidente que tudo não passava de puro acordo político. Dulce era extravagante, comunicativa, mantinha relações sociais com figuras da mídia brasileira, como Silvio Santos, ocupando, inclusive, um papel de maior destaque que seu marido nos meios de comunicação daquele momento. Embora Menem já tenha presidido a Argentina depois da ditadura, muitos hábitos conservadores foram recuperados. Tanto eles quanto nós ainda não havíamos abandonado, moralmente, o sistema autoritário.

Segundo Zulema Yoma, aquela carta foi responsável pelo atentado contra seu filho, morto no dia 15 de março de 1995. Nela, o jovem frequentador de discotecas, usuário de carros luxuosos e aviões particulares, faz denúncias genéricas sobre corrupção, levanta a hipótese do presidente ser refém de seus amigos e acusa a sua família de ter privilégios que ultrapassam o direito legal. Zulema juntou provas de que o helicóptero teria sido derrubado por tiros, mas ainda hoje isso não está provado na justiça argentina, embora em 10 de novembro de 1999, o jornal La Nación tenha publicado uma declaração de Carlos Menem, reconhecendo que a morte de seu filho fora um atentado. A luta de Zulema Yoma fez com que Norma Morandini a designasse por um sintagma que evidencia a persistência da mãe do filho morto: 'mãe-coragem'. Numa sociedade que ainda trazia na sua memória a morte de tantos filhos jovens, vítimas da ditadura militar, e que levou muitas mães e avós a se rebelarem, o discurso de Zulema Yoma encontra eco. Escreve Morandini:

Si las Madres de la Plaza de Mayo desnudaron el terror del poder militar, y al imponer la verdad triunfaron sobre las armas y el poderío, la obstinación de Zulema ataca a un poder difuso. Por momentos apunta sobre el presidente Menem, y en otros, lo convierte en un rehén de ese mismo poder que Zulema denuncia (MORANDINI, 1998, p. 162).

Talvez não haja nenhuma família argentina que não tenha sido vítima da violência militar. Todos perderam algum irmão, algum filho, algum neto, algum sobrinho, algum vizinho ou, na melhor/pior das hipóteses, algum compatriota. Essa ferida ainda está aberta e isso se sente no cinema e na literatura argentina desde então. Não poderia ser diferente com Norma Morandini: ela sente a sua dor na dor de Zulema e isso pode explicar a cumplicidade que estabelece com sua entrevistada.

El Harén, apesar de seu título sugestivo, que possibilita uma viagem à fantasia, está comprometido com parte da produção literária argentina daquele momento, ocupada em resistir ao embrutecimento de sociedades sem leitores do fim do milênio e de registrar a memória nacional. 


\section{PEQUENA CONCLUSÃO}

Para concluir essas apressadas reflexões, retomo as palavras de Mempo Giardinelli (Argentina, 1947), conhecedor exemplar da literatura de seu país. Orgulhosamente o escritor afirma que o discurso literário da Argentina, de certo modo, está na contramão do mercado editorial. Com otimismo e sem perder a lucidez, Giardinelli afirma que aquela literatura está comprometida com a Ética, embora tenha clareza de que haja, em palavras suas, depredadores da linguagem. Produções literárias como a de Liliana Heker, Norma Morandini e a dele próprio são, de certo modo, um luxo no contexto da realidade social latino-americana do fim do milênio passado. Essa realidade sombria, marcada pelo desencanto, pela violência e pela falta de solidariedade, ainda produz compromisso literário.

E para terminar de forma otimista e, assim, revelar meu jeito teimoso de ser, recupero algumas palavras de Eduardo Fracchia (1945-1999), sensível poeta chaquenho, que nos devolve a ilusão, propondo que:

[...] lo que necesitamos es una nueva concepción de hombre, por lo que la tarea es doble: no sólo debemos diseñar una forma de organización política - sin duda más equitativa - sino que, previamente, debemos imaginarnos de nuevo. $\mathrm{Y}$ a pesar de que se diga lo contrario, para esto son necesarias las utopías, los horizontes que en forma conjunta deben trazar las naciones. Todas. Sin excepción (FRACCHIA, 1997, p. 124)

\section{REFERÊNCIAS}

BAKHTIN, Mikail. Questões de Literatura e de Estética. A teoria do romance. São Paulo: Hucitec, 1993.

BARTHES, Roland. El placer del texto y lección inaugural. México: Siglo veintiuno, 1996.

FRACCHIA, Eduardo. Apuntes para una Filosofía de la Resistencia. Corrientes: EUDENE, 1997.

GIARDINELLI, Mempo. El país de las maravillas. Los argentinos en el fin del milenio. Buenos Aires: Planeta, 1998.

HEKER, Liliana. El fin de la historia. Buenos Aires: Alfaguara, 1996.

MENTON, Seymour. La nueva novela histórica de la América Latina: 1979-1992. México: FCE, 1993.

MORANDINI, Norma. El Harén. Los árabes y el poder político en la Argentina. Buenos Aires: Sudamericana, 1998.

RODRÍGUEZ, Alexis Márquez. Historia y ficción en la novela venezolana. Caracas: La Casa de Bello, 1991.

SZACKI, Jerzi. As utopias ou A felicidade imaginada. Rio de Janeiro: Paz e Terra, 1972. 